\title{
PRODUTOS À BASE DE BREU COMO AGENTES DE COLAGEM INTERNA EM SISTEMAS ALCALINOS: UM NOVO CONCEITO
}

\author{
I. R. SANTOS ${ }^{1}$, G. VENTORIM ${ }^{1}$ e J. C. CARASCHI ${ }^{1}$ \\ ${ }^{1}$ Universidade Estadual Paulista "Júlio de Mesquita Filho" - UNESP \\ E-mail para contato: ivan@itapeva.unesp.br
}

\begin{abstract}
RESUMO - Os papéis produzidos em sistemas alcalinos apresentam melhores propriedades dos que os produzidos em sistemas ácidos além de possibilitar a utilização de carbonato de cálcio como carga. Portanto torna-se necessária a busca por agentes de colagem mais eficientes para este tipo de processo. A presente pesquisa teve como objetivo viabilizar a utilização de breu como agente de colagem interna em meios neutro/alcalinos de produção de papel. Na pesquisa foi realizada a esterificação do breu seguida de pré-mixagem com PAC (Cloreto de polialumínio) em diferentes concentrações. As colas foram avaliadas em papéis formados por polpa industrial branqueada ECF, amido, PAC e cola. As folhas formadas com os aditivos foram avaliadas com relação à eficiência de colagem (Cobb, Edge Wicking Peroxide, Lactic Acid and Water) em linha de cobertura de papel cartão de $100 \mathrm{~g} / \mathrm{m}^{2}$. Os resultados provaram a eficiência da nova cola para os parâmetros avaliados.
\end{abstract}

\section{INTRODUÇÃO}

O termo colagem interna é usado por técnicos da área de produção de papel para descrever a prática de adição de produtos químicos visando aumentar a resistência do papel à absorção de água e/ou outros fluidos. Isto ocorre devido à alteração da energia livre da superfície da celulose, cujo motivo pode ser atribuído aos grupos hidroxila (devido à tendência de formar ligações de hidrogênio). O nível de colagem deve ser ajustado de acordo com os padrões de qualidade exigidos pelo tipo e finalidade do papel. A tendência é que papéis para embalagem necessitem de um maior grau de hidrofobicidade, portanto um maior nível de colagem enquanto que papéis de impressão e escrita necessitam de um nível de colagem mais ameno, visto que deve haver higroscopicidade suficiente para a fixação da tinta, seja de escrita ou impressão.

As principais funções de colagem são prevenir o espalhamento da tinta de impressão, ou de escrever, sobre o papel; tornar o papel mais resistente à penetração de umidade, sem torná-lo totalmente impermeável; tornar o papel mais consolidado e mais rígido; aumentar a retenção de fibras, cargas e outros materiais adicionados ao papel.

Durante muito tempo o sistema breu/alumina foi utilizado como agente de colagem interna do papel. Com o advento de sistemas alcalinos de produção, tornou-se necessário utilizar novos reagentes como o AKD (dímero de alquil-ceteno) e o ASA (anidrido alquenil succínico), pois o breu 
saponifica em meio alcalino e não permite a utilização de fillers de carbonato de cálcio (filler mais viável econômica e tecnologicamente) como os 2 agentes supracitados. Com o intuito de viabilizar a utilização do breu em sistemas de produção com $\mathrm{pH}$ alcalinos, pesquisadores têm realizado modificações tanto na estrutura do breu como na composição do mix a ser adicionado como agente de colagem no papel.

O presente trabalho foi realizado com papel cartão de embalagens Tetra Pak e teve como objetivo modificar uma cola industrial à base de breu de forma a possibilitar sua utilização em meio alcalino através da esterificação do breu seguida de pré-mixagem com policloreto de alumínio.

O breu convencional utilizado em sistemas ácidos de produção de papel não podem ser utilizados em condições de $\mathrm{pH}$ neutro ou alcalino. Entretanto, pesquisas têm sido realizadas, modificando-se os agentes de colagem à base de breu (rosin sizes) no sentido de viabilizar sua utilização também em processos de $\mathrm{pH}$ neutro/alcalino.

Existem vários motivos para viabilizar o uso deste tipo de composto em sistemas alcalino de produção de papel, dentre eles a facilidade de operação e obtenção, apresentam uma curva de colagem gradual, não dependem da formação de ligações covalentes, são compatíveis com wet-end additives, etc.

Hisken et al. (1989) e Katz et al. (2003) estudaram os efeitos da aplicação de sistemas polyaluminum chloride (PAC)/breu e alum/breu na colagem interna de papel. Resumidamente, os pesquisadores registraram as seguintes conclusões:

- Para ambos os sistemas, PAC/rosin e alum/rosin, uma pré-mixagem torna a colagem muito mais eficiente; a proporção ideal de PAC/breu é de 1,0:1,0 e alum/breu é de 1,5:1,0.

- Durante a pré-mixagem alum/breu, quanto menor a concentração e a temperatura de premixagem, melhor a colagem do papel.

Baseando-se nas pesquisas que utilizam breu esterificado e nas pesquisas que mostram que um premix de breu:PAC apresenta melhores resultados do que colagem reversa e convencional, propôs-se fazer uma união destas pesquisas e utilizar uma cola industrial como base.

\section{MATERIAL E MÉTODOS}

Os materiais utilizados na pesquisa e suas propriedades são apresentados abaixo.

Cola de breu comercial: A cola utilizada durante a pesquisa foi a mais utilizada industrialmente. Trata-se de uma emulsão catiônica de breu fortificado com ácido fumárico a 35\% de teor de sólidos e tamanho médio de partículas de $1 \mu \mathrm{m}$. amostra.

Glicerina: A glicerina utilizada é bi-destilada (99\% de pureza) e foi fornecida pela Cargill como 
Policloreto de alumínio: O agente "mordant" utilizado no pré-mix com cola de breu foi o PAC. Trata-se de uma solução amarelada límpida, com cheiro insignificante, completamente solúvel em água $\left(\mathrm{a} 20^{\circ} \mathrm{C}\right)$ e insolúvel em solventes orgânicos.

Químicos adicionais: Utilizou-se amido catiônico proveniente da linha de cobertura da MP9 Klabin Monte Alegre, agente de resistência a seco e AKD como químicos adicionais.

Polpa de celulose: A polpa de celulose utilizada foi fornecida pela empresa Klabin S/A. Trata-se de um mix branqueado (90\%ISO) e refinado $\left(40^{\circ} \mathrm{SR}\right)$ de $80 \%$ de fibras curtas e $20 \%$ de fibras longas utilizado para a produção da camada de cobertura do papel cartão produzido na MP9 da unidade de Monte Alegre-PR.

Os métodos utilizados durante a pesquisa estão descritos abaixo.

Preparação da cola: Primeiramente fez-se a reação da emulsão de cola com a glicerina em razão molar de 2:1 (excesso) para esterificação do breu em um béquer com agitação e temperatura de $90^{\circ} \mathrm{C}$ durante 1h. Depois foi realizado o pré-mix da mistura com o PAC em razões molares de 0,5, 1,0 e 1,5 mol de PAC por mol de breu (considerando a massa molecular do ácido abiético). As condições de pré-mix foram as mesmas utilizadas por ZOU et al. (2004).

Aplicação da cola: Primeiro foi ajustada a concentração mássica da polpa para $0,5 \%$. Os cálculos para aplicação de químicos foram feitos considerando-se $\mathrm{kg}$ de químicos (tal qual) por tonelada de polpa absolutamente seca. As dosagens utilizadas são as usuais da linha de cobertura da MP9 - Klabin Monte Alegre e são apresentadas na Tabela 1.

Tabela 1 - Dosagens utilizadas durante a aplicação

\begin{tabular}{|l|l|l|l|l|}
\hline Fennobond 786 & Amido Catiônico & AKD & PAX & Colas (breu) \\
\hline $3,5 \mathrm{Kg} / \mathrm{t}$ & $6 \mathrm{~kg} / \mathrm{t}$ & $3,5 \mathrm{Kg} / \mathrm{t}$ & $6,0 \mathrm{Kg} / \mathrm{t}$ & $10,0 \mathrm{Kg} / \mathrm{t}$ \\
\hline
\end{tabular}

As aplicações foram feitas com seringas com intervalos de 5 segundos entre os químicos. Ao término da aplicação foi mantida a polpa já com os químicos em agitação por 15 segundos antes da formação da folha. A folha foi formada com gramatura de $100 \mathrm{~g} / \mathrm{m}^{2}$ e posteriormente seca em secador de cilindro a $125^{\circ} \mathrm{C}$ durante 8 minutos (4/4).

Eficiência de colagem: Os parâmetros de eficiência de colagem analisados foram Cobb test, Edge wicking - peroxide e Edge wicking - lactic acid. A mais importante aplicação deste teste é nos papéis cartões utilizados em embalagem Longa Vida, que ficam em contato com sucos; leite e derivados; e outros líquidos.

O Cobb test foi realizado de acordo com a norma Tappi T-441 e os testes de edge wicking conforme o procedimento: 
1. Cortam-se corpos-de-prova de tamanho de 25 por 15 centímetros.

\section{Identifica-se a amostra.}

3. Depois de cortadas e identificadas, as amostras foram acondicionadas na estufa durante quinze minutos aproximadamente, a uma temperatura de $105^{\circ} \mathrm{C}$. Passado o tempo de cura, as amostras foram deixadas à temperatura ambiente por mais quinze minutos, para climatização. $\mathrm{O}$ tempo de cura é necessário para similar o tempo que a cola utilizada no cartão leva para alcançar todo a sua capacidade de repelência à água.

4. Na finalização da preparação das amostras, elas foram dividas em dois corpos-de-prova que foram plastificados com fita de poliéster nas duas faces em uma plastificadora e em seguida cortados numa guilhotina no formato padrão para este teste, que é de 2,5centímetros de largura por 7,5 centímetros de comprimento.

Após a plastificação e o corte final, um dos corpos-de-prova foi destinado ao teste com ácido lático, outro ao teste com peróxido.

O teste de Edge Wicking Peróxido tem como objetivo avaliar a quantidade de peróxido de hidrogênio absorvido pelas bordas dos corpos-de-prova.

Nele os dez corpos-de-prova, após serem pesados individualmente em balança analítica, com precisão de $0,001 \mathrm{~g}$, são colocados em um suporte de porcelana, que é então submerso em um equipamento especifico para este teste. Neste equipamento há uma solução de peróxido de hidrogênio a $35 \%$, e estando à uma temperatura de $70 \pm 1^{\circ} \mathrm{C}$. Ao se colocar o suporte de porcelana com os corpos-de-prova, a solução deverá cobrir as amostras numa altura de um centímetro.

As amostras permanecem sob esta solução por 10 minutos. Após isto são retiradas, colocadas entre folhas de papel absorvente, e pressionadas levemente entre as folhas. Procedimento necessário para se retirar o excesso de peróxido de hidrogênio presente sobre as amostras. Retirado o excesso as amostras são novamente pesadas.

Com a massa inicial e a massa final de cada corpo-de-prova, mais o valor da espessura do cartão, é possível se calcular a quantidade de peróxido de hidrogênio absorvido. A equação utilizada para o calculo é:

$$
E w p=\frac{(M f-M i) \times 5}{\frac{e}{1000}}
$$

Onde,

Ewp é o valor de peróxido absorvido dado em $\mathrm{kg} / \mathrm{m}^{2} .10 \mathrm{~min}$; 
$M f$ e $M i$ são, respectivamente,as massas finais e iniciais dos corpos-de-prova, expressas em g;

$e$ é o valor da espessura do cartão;

5 é o fator de conversão do perímetro do corpo-de-prova de 0,2m para 1m;

1000 é o fator para conversão de $\mu \mathrm{m}$ para mm.

Esta fórmula também é válida para o Edge wicking lactic acid, que é realizado colocando-se os corpos-de-prova em ácido lático a 1\% durante 60 minutos.

\section{RESULTADOS}

\subsection{Cobb test}

Os resultados de Cobb test são apresentados na Figura 1 e mostram um melhor desempenho da nova cola quando comparado à cola industrial KN 10/35 e pouca variação em função do $\mathrm{pH}$, o que mostra ser possível trabalhar com um $\mathrm{pH}=8,0$ para este parâmetro.

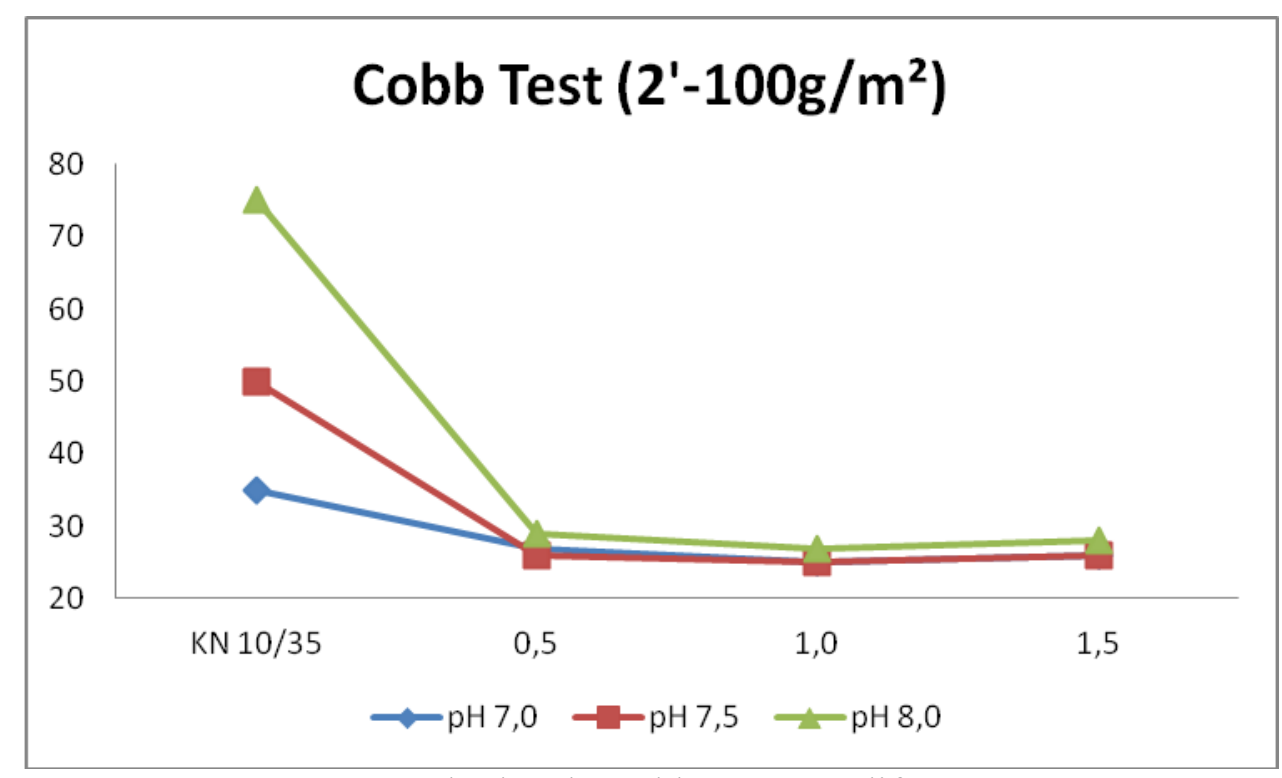

Figura 1 - Resultados de Cobb test para diferentes $\mathrm{pH}$ 's.

Os resultados mostram o valor de Cobb test de 3 pré-mixes $(0,5: 1,0 ; 1,0: 1,0 ; 1,0: 1,5)$ e da cola industrial escolhida como base (KN 10/35 - Kemira Chemicals Ltda) em diferentes faixas de $\mathrm{pH}$. Quanto menor o valor de Cobb, melhor o desempenho da cola, pois menor a absorção da água pelo 
papel. O pré-mix que apresentou melhor resultado foi de 1,0:1,0. Todos os pré-mixes apresentaram melhores reultados de Cobb quando comparados à cola industrial sem a modificação proposta, o que evidencia a melhoria para a nova cola.

\subsection{Edge Wicking Peroxide}

Os resultados de Edge wicking peroxide são apresentados na Figura 2 e mostram a eficiência maior para o mix 1:1 de breu esterificado para PAC.

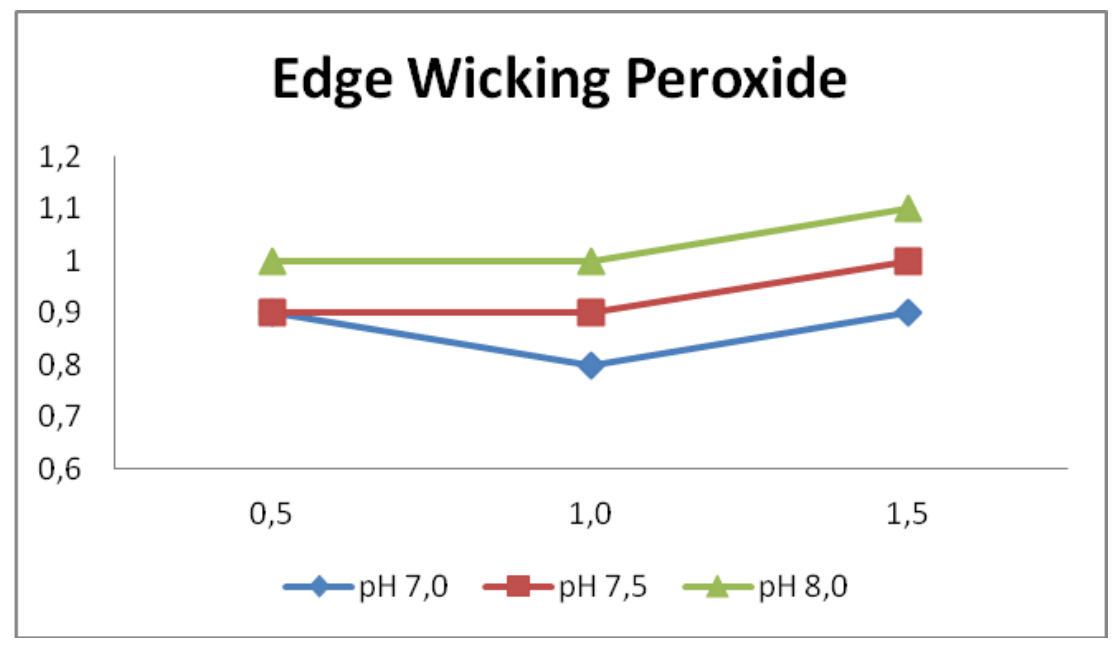

Figura 2 - Resultados de Edge wicking peroxide para diferentes pH's.

Os resultados mostram o valor de Edge Wicking Peroxide (EWP) de 3 pré-mixes (0,5:1,0; $1,0: 1,0 ; 1,0: 1,5)$ em diferentes faixas de $\mathrm{pH}$. Quanto menor o valor de EWP, melhor o desempenho da cola, pois menor a absorção de peróxido pelo papel cartão, pois o mesmo é exposto a um banho de peróxido de hidrogênio para esterilização, pois o mesmo é utilizado para produção de embalagens Tetra Pak.

Os pré-mixes que apresentaram melhores resultados foram de 1,0:1,0 e 0,5:1,0, sendo que para o teste de Tukey estes dois não diferiram entre si.

Os valores estão dentro da faixa aceita pela empresa na produção de papel cartão.

\subsection{Edge Wicking Latic Acid}

Os resultados de Edge wicking latic acid são apresentados na Figura 3 e mostram a eficiência maior para o mix 1:1 de breu esterificado para PAC 


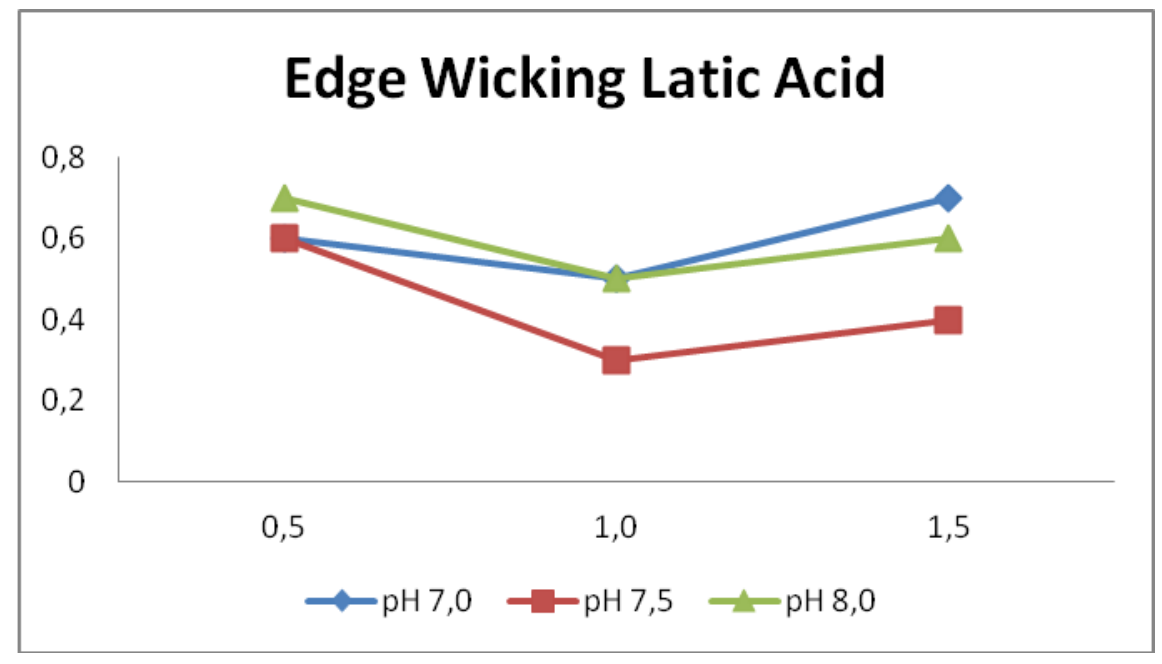

Figura 3 - Resultados de Edge wicking latic acid para diferentes pH's.

Os resultados mostram o valor de Edge Wicking Latic Acid (EWLA) de 3 pré-mixes (0,5:1,0; $1,0: 1,0 ; 1,0: 1,5)$ em diferentes faixas de $\mathrm{pH}$. Quanto menor o valor de EWLA, melhor o desempenho da cola, pois menor a absorção de ácido lático pelo papel cartão, que normalmente é exposto a este ácido.

O pré-mix que apresentou melhor resultado foi de 1,0:1,0. Os valores estão dentro da faixa aceita pela empresa na produção de papel cartão, que evidencia a possibilidade da utilização da cola em escala industrial.

\section{CONCLUSÕES}

Para os três parâmetros analisados a nova cola apresentou resultados positivos, sendo que a melhor faixa de pré-mixagem foi a de 1,0:1,0.

As colas apresentaram melhor desempenho que a utilizada industrialmente nos $\mathrm{pH}$ 's de 7,0 a 8,0 .

O breu esterificado apresenta melhor desempenho que o breu fortificado com ácido fumárico (utilizado na cola industrial convencional).

\section{REFERÊNCIAS}

HISKENS, I. R. Paper sizing methods and compositions. Eur. pat. 333368 (1989)

KATZ, G., HOUSE, L. W. Internal paper sizing improvements, U.S. pat. 6540877 (2003) 
19 a 22 de outubro de 2014

Florianópolis/SC

ZOU, Y., HSIEH, J. S., WANG, T. S. Rosin sizing under neutral-alkaline papermaking conditions. TAPPI Journal, Vol. 3; n.7; 2004. 